Alejandra Saladino

\title{
Museus e Arqueologia: algumas reflexões
}

Alejandra Saladino ${ }^{1}$

A história de um conceito não é, de forma alguma, a de seu refinamento progressivo, de sua racionalidade continuamente crescente, de seu gradiente de abstração, mas a de seus diversos campos de constituição e de validade, a de suas regras sucessivas de uso, a dos meios teóricos múltiplos em que foi realizada e concluída sua elaboração. Canguilhem

\section{Resumo}

O presente artigo resulta de uma reflexão preliminar sobre os museus de arqueologia que parte da observação do setor museológico do Brasil, mas que eventualmente pode estender-se a contextos nos quais a preservação e musealização das referências patrimoniais arqueológicas são afetadas pela dinâmica da Arqueologia de Contrato. O objetivo deste texto é iniciar uma reflexão sobre algumas questões conceituais e metodológicas referentes aos museus de arqueologia, designadamente, as especificidades desse tipo de museu, as temáticas passíveis de abordagem, o perfil dos museus que adotam a gramática da

1 Museóloga, professora adjunta do Departamento de Estudos e Processos Museológicos (CCHS/UNIRIO), professora colaboradora do Mestrado Profissionalizante em Preservação do Patrimônio Cultural (Centro Lúcio Costa/IPHAN) e do Programa de Pós-Graduação em Museologia e Patrimônio (PPGP-MUS/UNIRIO) e museóloga do Museu da República (MR/Ibram/MinC). 
Museus e arqueologia: algumas reflexões

Sociomuseologia e da Arqueologia Pública, a aplicação de estratégias museográficas para diminuir o gap entre o discurso das exposições de longa duração em relação ao desenvolvimento das pesquisas arqueológicas e os desafios da gestão das coleções arqueológicas decorrentes do desenvolvimento da Arqueologia de Contrato. A metodologia aplicada concentra-se na revisão bibliográfica sobre o tema e na observação empírica sobre o contexto brasileiro. As considerações a destacar desta reflexão preliminar dizem respeito à urgência do estabelecimento de uma agenda de trabalho coletivo e colaborativo dos diversos profissionais envolvidos nos processos de preservação do patrimônio arqueológico para que os museus exerçam sua plena potência enquanto loci de apropriação e ressignificação das referências patrimoniais arqueológicas.

Palavras-chave: Museus; Arqueologia; Sociomuseologia; Arqueologia Pública

\section{Abstract}

This article results from a preliminary thoughts about museums of archeology that part of the observation of the museum sector in Brazil, but it might eventually extend to contexts in which the preservation of archaeological heritage and musealization references are affected by the dynamics of Contract Archaeology . The aim of this paper is to initiate a reflection on some conceptual and methodological issues relating to archaeological museums, notably the specifics of this kind of museum, the theme can be approached, the profile of museums that adopt the grammar of Sociomuseologia and Public Archaeology applying museographic strategies to decrease the gap between the discourse of the permanent exhibitions in the development of archaeological research and the challenges of managing archeological collections from the development of Contract Archaeology. The methodology focuses on the literature review on the subject and empirical 
observation about the Brazilian context. Considerations to highlight this preliminary thoughts concerning the urgency of establishing an agenda for collective and collaborative work of the various professionals involved in the processes of preservation of archaeological heritage museums to exert their full power while loci of appropriation and reinterpretation of the archaeological heritage references .

Keywords: museums, Archaeology, Sociomuseologia, Public Archaeology

\section{Introdução}

O que é um museu de arqueologia? Quais são suas especificidades? Quais temáticas podem ser abordadas? Melhor, quais temas devem ser abordados quando se impõe o objetivo de romper com sentenças recorrentes no imaginário social como, por exemplo, que o museu é lugar de coisa velha e que a Arqueologia estuda os cacos e as múmias e, a pior versão dentre todas, "escava dinossauros"? Qual o perfil de um museu de arqueologia alinhado à Sociomuseologia ${ }^{2}$ e à Arqueologia Pública ${ }^{3}$ ? Quais as estratégias adequadas para diminuir o gap entre as narrativas resultantes das pesquisas arqueológicas mais recentes e o discurso da exposição de

2 Sociomuseologia: área multidisciplinar que visa consolidar 0 reconhecimento da museologia como recurso para o desenvolvimento da humanidade, assente na igualdade de oportunidades e na inclusão social e econômica (MOUTINHO, 2012).

3 Arqueologia Pública: decorrente da reflexão sobre a função social da ciência e do cientista, este termo designa, de acordo com o historiador Ulpiano Bezerra de Meneses (2007:54) o campo de atuação extramuros acadêmicos a partir do qual, considerando o componente corporal/sensorial/físico da condição humana, o trabalho humano e a apropriação do espaço poderia contribuir para a formação crítica e o surgimento e reforço da consciência política. Destarte, a Arqueologia Pública pode ser compreendida como a prática comprometida com a divulgação e a apropriação do discurso científico e do patrimônio arqueológico. 
Museus e arqueologia: algumas reflexões

longa duração dos museus? Quais seriam os maiores desafios dos museus nos tempos do crescimento exponencial dos acervos arqueológicos resultante da Arqueologia de Contrato ${ }^{4}$ ?

As motivações para refletir sobre essas questões, objetivos deste artigo, decorrem da observação empírica sobre a notada dificuldade de algumas instituições museológicas brasileiras de romperem com pré-noções do senso comum e proporem uma outra percepção sobre a Arqueologia e sobre a própria instituição. Decorre da observação de que, em certa medida, os museus de arqueologia são especialmente afetados pelas imagens reducionistas que grassam no imaginário social. Em outras palavras, decorre da observação de que a imagem de museu como lugar de coisa velha e de coisa antiga (CHAGAS, 1987) é potencializada

4 Arqueologia de Contrato: No Brasil, Arqueologia de Contrato, ou Arqueologia Consultiva ou Arqueologia Empresarial, define a prática profissional vinculada ao desenvolvimento de empreendimentos de qualquer porte mas no âmbito do licenciamento ambiental. Sobre o tema, faz-se necessária a exposição de dois esclarecimentos, ambos de ordem conceitual. Embora haja diferenças de vinculação e de dinâmica entre Arqueologia Acadêmica (atrelada ao campo científico e conformada em seus tempos) e a Arqueologia de Contrato (atrelada ao campo econômico, à lógica de mercado e ao cronograma dos empreendimentos, do qual é rigorosamente uma etapa prévia), percebo ser contraproducente e mesmo um risco insistir em tal diferenciação, pois, efetivamente não há entre as práticas, e não deveria haver, qualquer diferença de caráter teóricometodológico $\mathrm{O}$ último ponto a esclarecer refere-se a reconhecer o termo Arqueologia Preventiva como sinônimo da Arqueologia de Contrato. Sobre essa questão, alinho-me à percepção do historiador Mario Polo Alves Junior (2014) de que a prática da Arqueologia de Contrato no Brasil não deve ainda ser associada ao conceito de Arqueologia Preventiva. $O$ autor argumenta que na maioria dos projetos não são desenvolvidas ações associáveis ao conceito de prevenção, designadamente a identificação e mapeamento de áreas de baixa, média e alta relevância arqueológica. Antes sim, conforme o autor, que analisa a aplicação dos Termos de Ajustamento de Conduta (TAC) nos casos de dano ao patrimônio arqueológico, no Brasil é praticada uma Arqueologia Póstuma (ALVES; JR, 2014:165) 
quando associada aos museus de arqueologia, pois seus acervos continuam inacessíveis para boa parte do público que não detém os códigos necessários para compreendê-los. Decorre ainda da percepção de que por trás de cada ação de divulgação da Arqueologia há uma ideologia que resulta das idéias, crenças $e$ ações impostas e assumidas, conscientemente ou não (ZAPATERO, 2009:17, tradução nossa) de parte de cada indivíduo envolvido nesse processo (arqueólogos, museólogos e educadores, apenas para citar alguns). Decorre, por fim, da observação da complexificação da gestão dos acervos arqueológicos resultante do licenciamento ambiental/Arqueologia de Contrato. E, por tudo isso percebo serem estes temas de importância fundamental para que a atuação de museólogos - enquanto produtores de novos sentidos a partir da decodificação de discursos e gestores do patrimônio musealizado - contribua efetivamente para a apropriação, ressignificação e valorização das referências patrimoniais arqueológicas.

Parto do pressuposto de que o museu é lócus privilegiado para a preservação e valorização do patrimônio arqueológico, pois nesse lugar de memória ${ }^{5}$ (NORA, 1993) encontram-se, a princípio, ferramentas para tal, designadamente as etapas que configuram a cadeia operatória da Museologia ou o próprio processo de musealização (constituído por ações de documentação, investigação e comunicação) ${ }^{6}$. Por isso, meu argumento é exposto

${ }^{5}$ Lugar de memória: noção forjada pelo historiador Pierre Nora para definir espaços materiais, simbólicos e funcionais, onde memória e história estão imbricadas em um jogo político de vontade de memória e intenção de memória (NORA, 1993:22).

${ }^{6}$ De acordo com a museóloga Cristina Bruno (1997:1), a musealização do patrimônio arqueológico

... organiza-se a partir de estudos relacionados à cadeia operatória de procedimentos museológicos de salvaguarda (conservação e documentação) e comunicação (exposição e atividades educativoculturais), aplicados à realidade arqueológica, constituída a partir de 
Museus e arqueologia: algumas reflexões

de acordo com uma estrutura que se inicia com uma breve contextualização seguida de uma reflexão sobre os conceitos de museu e de Arqueologia e, finalmente, de uma discussão sobre as potencialidades e desafios dos museus arqueológicos na atualidade.

\section{Museus e Arqueologia: uma rápida prospecção}

As possíveis conexões entre museus e arqueologia podem se estendidas até a antiguidade e têm na prática do colecionismo e todas suas estratégias de conformação o seu elo. $O$ hábito de colecionar espólios de guerra e tesouros retirados das entranhas das terras conquistadas, bem como das próprias, fez parte das práticas culturais de distintos povos. Mas foi efetivamente com o ressurgimento dos ideais humanistas na Europa Ocidental do século $\mathrm{XV}$ que foram estabelecidas as bases comuns dos museus e da arqueologia.

Sob a égide do antiquariato, a catalogação e o inventário foram os instrumentos utilizados para a sistematização das práticas de ordenamento do conhecimento sobre os registros arqueológicos, já a partir do século XV, e igualmente da organização das coleções que deram origem aos gabinetes de curiosidade do século XVII.

Segundo Francisca Hernández Hernández (2010:20), os ares iluministas foram providenciais para o desenvolvimento das ciências modernas e, consequentemente, para a consolidação do pensamento moderno e para o desenvolvimento da museografia ${ }^{7}$. Como inovação deste período, a autora destaca a taxonomia

referências patrimoniais, coleções e acervos. Por um lado, estes estudos buscam o gerenciamento e preservação destes bens patrimoniais e, por outro, têm a potencialidade de cultivar a noções de identidade $e$ pertencimento.

5 Em 1727, o marchand Friederich Neickel publicou um conjuto de proposições e normas para a classificação, conservação, estudo e exposição de objetos intitulado Museographia (HERNÁNDEZ, 2010:21). 
empirista, um sistema de classificação fundado na morfologia comparada. Essa forma de perceber o mundo reside no cerne das disciplinas científicas - Arqueologia dentre elas -, as quais lançam mão do método comparativo, da observação detalhista das experiências... e da observação contínua de padrões, com vistas à elaboração de leis gerais aplicáveis aos fenômenos biológicos e evolutivos (HERNÁNDEZ, 2010:20).

Entretanto, o ordenamento das coleções arqueológicas dos museus europeus se deve à experiência de Thomsen no ordenamento de sua própria coleção de numismática. 0 arqueólogo dinamarquês, justamente por conta do conhecimento adquirido ao longo da catalogação de sua coleção, foi convidado para organizar o acervo do Museu Nacional da Dinamarca. Desenvolveu então um sistema de classificação de acordo com o material. Nasceu assim o sistema de caráter empirista e de lógica positivista conhecido como Três Idades - da Pedra, do Bronze e do Ferro (TRIGGER, 2004: 82; HERNÁNDEZ, 2010:21), ainda hoje uma diretriz para muitas exposições arqueológicas. ${ }^{8}$

Assim, os museus nacionais do século XIX foram conformados enquanto lugares de memória nos quais eram identificadas - pela sistemática organização e estudo das coleções arqueológicas - como loci de desenvolvimento da arqueologia científica e do método tipológico comparativo aplicado na exposição das peças que remetem aos grupos culturais ancestrais das sociedades modernas. Por tudo isso, podemos perceber a relação da arqueologia e da gestão das coleções arqueológicas com o projeto de invenção dos estados nacionais europeus (ANDERSON, 1991). Afinal, nos museus, das mais potentes ferramentas

${ }^{8}$ Hernández (2010:21), dentre as maneiras de organização da coelções desenvolvidas no século XIX, destaca o sistema de cassificação tipológicocomparativo de organização dos objetos de acordo com suas características físicas e formais desenvolvido por Hildebrand para os acervos arqueológicos da Suécia. 
Museus e arqueologia: algumas reflexões

ideológicas, foram legitimadas as representações coletivas, construtos dos discursos políticos daquela altura. Nesses lugares de construção da memória histórica foram guardados os tesouros das elites e também aqueles coletados durante as expedições científicas do século XIX.

A preocupação com a extroversão e a apropriação dos discursos expositivos já estava presente nesses museus nacionais. Em 1822, o assessor da Glipoteca de Munique, Johann W. Goethe, publicou o artigo Arte $e$ Antiguidade, uma reflexão sobre a exposição em museus e a diversidade de públicos, que demanda a elaboração de discursos em distintos níveis (HERNÁNDEZ, 2010:21). Desde então problematizados e criados esquemas expositivos. Hernández (2010:23-35) sistematiza as distintas museografias que, a grosso modo, ou são decorrentes da idéia de que as exposições devem pura e simplesmente expor objetos ou da idéia de que as exposições devem apresentar uma série de meios que as tornem mais acessíveis aos diversos públicos ${ }^{9}$, mas destaca que, na atualidade, os museus arqueológicos tendem a mesclar as distintas museografias com o intuito de realizar representações cenográficas muito diversas ${ }^{10}$ (HERNÁNDEZ, 2010:37).

${ }^{9}$ Hernández ordena as museografias existentes em dois grandes grupos: exógenas e endógenas. Nas primeiras, os objetos definem a lógica das exposições e a extroversão das peças obedece a uma ordem previamente estabelecida, que deve ser de conhecimento dos visitantes; ou seja, estes devem possuir conhecimentos mínimos sobre os temas e objetos expostos, os quais são tomados como objetos de estudo (HERNÁNDEZ, 2010:23). Já nas segundas, a disposição das peças obedece às demandas da própria exposição. Em outras palavras, a cenografia do conjunto é criada a partir das mensagens que se quer transmitir, bem como da recepção e apropriação dos objetos pelos visitantes (HERNÁNDEZ, 2010:30). Portanto, não há necessidade de detenção de códigos nem de conhecimentos prévios para a compreensão e recepção do discurso expositivo.

${ }^{10}$ Hernández destaca a museografia analógica - que cria exposições nas quais são reproduzidos os contextos arqueológicos originais - e a museografia de imersão - que cria exposições que promovem experiências plurisensoriais ao inserir o público em reproduções integrais dos contextos 
No Brasil, a relação entre museus e Arqueologia é igualmente digna de nota, se considerarmos a trajetória de instituições como o Museu Nacional, o Museu Paulista e o Museu Paraense Emilio Goeldi (SCHWARCZ, 2004). É inconteste a importância desses lugares de memória para a conformação e o desenvolvimento da Arqueologia no país até os dias de hoje. No século $\mathrm{XX}$, a conexão entre formação de acervos arqueológicos e desenvolvimento da Arqueologia continuou forte, ainda que as universidades e seus departamentos de Antropologia e Arqueologia tenham entrado em cena.

A arqueóloga Cristiana Barreto (2000) aponta que o desenvolvimento do campo da Arqueologia no Brasil está relacionado às articulações em prol da preservação do patrimônio arqueológico $^{11}$. A autora exemplifica sua posição com a fundação de alguns órgãos - designadamente o criado por Castro Faria, o Instituto de Pré-História, criado por Paulo Duarte e o Centro de Pesquisas Arqueológicas (CEPA), criado por Loureiro Fernandes - os quais foram

frutos de uma política preservacionista antes de mais nada preocupada em garantir os direitos à pesquisa científica de um patrimônio em crescente destruição, surgindo praticamente à margem do projetos intelectuais mis amplos do ensino das ciências sociais no Brasil (BARRETO, 2000:40).

Destarte, a Arqueologia Brasileira do século XX é tributária da ação articulada dos atores sociais supracitados pois seus

arqueológicos - que, somadas à adoção de recursos tecnológicos, permitem criar uma realidade difícil de reproduzir por outros meios tradicionais (HERNÁNDEZ, 2010:37)

${ }^{11}$ De acordo com Meneses (2007:40), a pesquisa arqueológica é o ponto de partida da gestão do patrimônio arqueológico. 
Museus e arqueologia: algumas reflexões

esforços somados resultaram em diversos cursos realizados no CEPA, vinculado à Universidade Federal do Paraná e em expedições e pesquisas sobre os sambaquis meridionais e outros sítios arqueológicos, designadamente as cavernas de Lagoa Santa, em Minas Gerais, e sítios na região amazônica, empreendidas por renomados arqueólogos da época, como Wesley Hurt, Betty Meggers e Annete Laming-Empreraire, além da homologação da Lei no 3.924, de 26 de julho de 1061, que dispõe sobre a proteção do patrimônio arqueológico brasileiro (LIMA, s.d.)

No século XXI, como resultado de uma complexa rede de eventos - dos quais se destacam a consolidação da legislação ambiental e do estabelecimento da Arqueologia de Contrato, a qual podemos compreender como o produto da interseção dos campos científico, político, econômico e jurídico-legal e seus respectivos interesses - (SALADINO, 2010; SALADINO, COSTA, MENDONÇA, 2013) a relação em tela complexificou-se. Os acervos arqueológicos, crescendo em escala exponencial (BRUNO \& ZANETTINI, 2007; WICHERS, 2010), abarrotam as reservas técnicas dos museus, que soam incapazes de implantar uma política de gestão que assegure a preservação, a investigação e a socialização dessas referências patrimoniais.

Ao findar esta breve prospecção topográfica sobre os caminhos cruzados e sobrepostos dos museus e da Arqueologia, finalmente temos condições de compreender esses lugares de memória e esse campo científico e identificar as fragilidades potencialidades dos museus de arqueologia, questões tratadas no item a seguir.

\section{Um olhar sobre os Museus de Arqueologia: potencialidades e desafios}

Iniciamos esta etapa da nossa reflexão lançando mão da citação que inaugura este texto, na qual Canguilhem nos alerta para a plasticidade dos conceitos, decorrente das diversas perspectivas e 
apropriações. Tudo isto para ressaltar que hoje os museus, mais que depósitos de tesouros, de coisas boas e más de lembrar, templos de legitimação e sacralização das raízes culturais, representações e mitos nacionais, são percebidos como lugares de reescrita da história a partir da reconstrução das memórias coletivas, como ferramentas de transformação e empoderamento social $^{12}$ e espaços de sociabilidade e de consumo cultural. Por sua vez, a Arqueologia, ainda que etimologicamente atrelada ao estudo do antigo, cada vez mais, e a partir de diversas perspectivas teóricas, trata da condição humana e da relação da nossa espécie com o meio a partir da cultura material e sem limitação de caráter cronológico (FUNARI, 2001) ${ }^{13}$.

Percebo que a discussão sobre as potencialidades e limitações dos museus arqueológicos deve iniciar-se na sua dimensão política. É preciso reconhecer que os museus e o discurso arqueológico resultam de processos de cunho político, pois de acordo com a arqueóloga Camila Wichers são conformados por seleções (de objetos a coletar e expor, de temas a investigar e a comunicar e de perspectivas teóricas a fundamentar as narrativas) que projetam apenas parte do contexto arqueológico na esfera patrimonial (WICHERS, 2010:27). Então, para que exerçam sua plena potência, os museus de arqueologia necessitam assumir a

${ }^{12}$ Hernández alinha-se a Murphy (2004) e assinala que essa transformação conceitual dos museus - inscrita na definição da Carta de Santiago do Chile, de 1972 - decorre do movimento de maio de 1968, que afetou todasas instituições europeias.

${ }_{13}$ Este aspecto é percebido de distintas formas no campo arqueológico, resultado de entendimentos diferentes sobre o conceito de antigo e do desenvolvimento, na América, da Arqueologia Histórica. Neste ensaio aplico a definição de Arqueologia como a ciência que estuda os sistemas e processos socioculturais extintos a partir da cultura material decorrente. 
Museus e arqueologia: algumas reflexões

dimensão política e ideológica tanto do discurso arqueológico quanto do discurso museológico ${ }^{14}$, bem como das suas coleções ${ }^{15}$.

Isto significa abdicar de apresentar ao visitante um discurso pretensamente neutro, objetivo, definitivo e acabado. Em outras palavras, significa assumir a pluralidade de perspectivas teóricas que conformam o conhecimento arqueológico, bem como seus limites, decorrentes dos processos seletivos que conformam as coleções arqueológicas investigadas e musealizadas e da própria dinâmica do campo científico, ditada pela constante revisão dos resultados de pesquisas mediante a obtenção de novos dados e/ou a incorporação de metodologias e instrumentos mais modernos. Significa ainda abandonar a comodidade da pasteurização do passado em nome da necessidade didática da exposição. Em outras palavras, significa deixar de escamotear as áreas de ignorância presentes no campo da Arqueologia e de essencializar os grupos sociais do passado, ocultando os conflitos sociais (ZAPATERO, 2009:25 tradução nossa) ${ }^{16}$.

Os arqueólogos pós-procesualistas Michael Shanks e Christopher Tilley $(1992)^{17}$ reconhecem o importante papel de elo

${ }^{14}$ Vale ressaltar que a observação apresentada sobre o caráter político e ideológico dos discursos é consonante à gramática foucaultiana (FOUCAULT, 1979; 1985; 1992).

${ }^{15}$ Zapatero (2009:17) reconhece que, a grosso modo, as ideologias dos poderes políticos se apropriam dos passados nacional e regionais para valorizá-los e rentabilizá-los nas agendas políticas contemporâneas com vistas a fortalecer o sentimento de pertencimento e as representações coletivas e legitimar os organismos governamentais.

${ }^{16}$ Vale ressaltar que a tendência de não evidenciar a heterogeneidade e a dissonância dos grupos sociais do passado advém da perspectiva históricoculturalista e da influência que o conceito de cultura arqueológica ainda exerce nos discursos expositivos.

${ }^{17}$ É no bojo das Arqueologias Pós-Processualistas - dentre as quais se destacam a Arqueologia Contextual, a Arqueologia de Gênero e a Arqueologia Indigenista, apenas para citar algumas - que a a dimensão política da Arqueologia e a função social do arqueólogo se torna um tema 
que os museus arqueológicos desempenham entre a Arqueologia enquanto campo científico e prática profissional - e o grande público não-arqueólogo (SHANKS, TILLEY, 1992). Esses museus são, em todas as suas modalidades (tradicionais ou de sítio), uma das formas mais diretas, eficazes e impactantes de divulgar o passado (MERRIMAN; MASRIERA; MANSILLA; MOSER, SANTACANA \& HERNÁNDEZ; WOOD \& COTTON apud ZAPATERO, 2009:25) Destarte, percebemo-los à luz da Sociomuseologia e da Arqueologia Pública como potentes loci de problematização e reflexão sobre os discursos científicos, de musealização de memórias de grupos sociais tradicionalmente emudecidos e/ou ausentes nas narrativas da memória histórica ${ }^{18}$ e de debate sobre temas candentes da atualidade, como os que tratam da relação entre nossa espécie e o ambiente $^{19}$.

Entretanto, é preciso admitir que aos museus de arqueologia cabe enfrentar o desafio de tornar significativas e ressonantes referências patrimoniais que, à primeira vista não passam de cacos de coisas feitas por uma gente desaparecida que não guarda relação alguma com a sociedade atual. Afinal, os objetos arqueológicos estão duplamente descontextualizados, pois que desvinculados de seus contextos arqueológicos e - por conta disso - expostos sem seus contextos de valor, uso e significação na

de debate e um aspecto a considerar durante o desenvolvimento das investigações.

${ }^{18}$ São inúmeras as investigações que trazem importantes dados sobre a diversidade e complexidade cultural de grupos culturais pré-coloniais, bem como sobre a conformação da sociedade brasileira e o papel das minorias e grupos subordinados nesse processo. A título de ilustração, citamos as investigações sobre a cultura sambaquiana (DeBLASIS \& GASPAR ); sobre a serra da Barriga e o Quilombo dos Palmares (FUNARI, 1995/1996) e o cemitério dos Pretos Novos (TAVARES, 2012).

${ }^{19}$ Apoiadas em Sabloff (apud ZAPATERO, 2009:15), destacamos a pertinência e a propriedade do discurso arqueológico para tratar dos temas socioambientais referentes à evolução das paisagens e à interferência dos grupos sociais nesses processos. 
Museus e arqueologia: algumas reflexões

sociedade que os elaborou, utilizou e descartou (ZAPATERO, 2009:26).

Assim evidencia-se o desafio dos museus de arqueologia: elaborar discursos que, a partir da contextualização dos vestígios arqueológicos, contribuam para a reflexão sobre a condição humana e para a apropriação e valorização do patrimônio arqueológico, tudo isto a partir de experiências museais sensoriais e afetivas. De acordo com a Carta de Lausanne (UNESCO, 2010), patrimônio arqueológico é patrimônio da humanidade, independente das representações - de nível nacional, regional e local - que possam ser associadas a ele. E aí reside a potência dos museus de arqueologia: criar discursos transversais, que possam contribuir tanto para o reconhecimento e reflexão das identidades e memórias sociais, quanto, e a partir delas, provocar a reflexão sobre temas candentes, como o multiculturalismo, a diversidade étnica e a condição humana.

O arqueólogo Gonzalo Ruiz Zapatero (2009:31), alinhado aos debates pós-processualistas sobre a função social da Arqueologia e do arqueólogo e dedicado à reflexão sobre a extroversão do discurso arqueológico, destaca que este profissional é responsável tanto pela divulgação social dos resultados de suas investigações quanto da divulgação realizada por não-arqueólogos. Destarte, fica evidente a necessidade do trabalho colaborativo entre arqueólogos, museólogos e demais atores (incluindo comunidades afetadas) para a divulgação da Arqueologia nos museus.

Zapatero (2009:16) percebe que a divulgação arqueológica orbita em torno das noções de "passado fechado" e "passado total" e denuncia o reducionismo das narrativas fundamentadas nessas premissas e sua vinculação a certas ideologias. $O$ autor ainda ressalta a pertinência de produzir discursos que partam da noção de "passado aberto" para que comportem distintas e opostas interpretações de um mesmo processo e de "passado 
fragmentário", pois que do passado efetivamente recuperamos alguns vestígios. Entretanto, o autor reconhece que a solução não é tão simples quanto estruturar as narrativas nos binômios "passado fechado/aberto" e "passado total/fragmentado", uma vez que $o$ passado arqueológico pode apresentar valores específicos $e$ diferentes de "aberto" e "fragmentário" (ZAPATERO, 2009:16, tradução nossa). Esta é uma questão de suma importância para a elaboração dos discursos dos museus atuais, que visam mais que "educar" pela comunicação de conteúdos, instigar o visitante a refletir sobre as coisas do passado e sua relação com o presente.

A divulgação do discurso arqueológico nos museus se dá pela exposição, uma das formas de extroversão que constituem a musealização do patrimônio arqueológico. Uma exposição arqueológica é resultado da aplicação de uma cadeia operatória que se inicia no contexto arqueológico - no qual o arqueólogo é o responsável pela seleção, coleta, análise e interpretação do material arqueológico - e segue no contexto museológico - onde, idealmente, museólogos, arqueólogos, educadores e segmentos sociais envolvidos (como comunidades locais, descendentes de sistemas culturais etc) decodificam o discurso arqueológico em discurso museológico - onde são produzidos diversos produtos educativo-culturais ${ }^{20}$. Vale ainda ressaltar que a conformação e a dinâmica da referida cadeia operatória estão rigorosamente atreladas ao contexto social, político, econômico e cultural vigente.

Graças à consolidação das premissas da Carta de Santiago do Chile, nas exposições museológicas deve se analisado 0 significado social e cultural que possuem (NIGAN apud HERNÁNDEZ, 2010:212, tradução nossa) os objetos. É preciso comunicar uma mensagem que sirva para fazer pensar, refletir e emocionar os visitantes (HERNÁNDEZ, 2010:40, tradução nossa). É preciso afetar

${ }^{20}$ Além das exposições, são produzidas diversas atividades experimentais, visitas mediadas, oficinas, cursos etc, e materiais de apoio variados, como material didático e publicações de toda sorte. 
Museus e arqueologia: algumas reflexões

pelo afeto, promover a mudança social, o que revela a importância do processo decodificação do discurso museológico e da dimensão didática da experiência museal.

Todavia, faz-se mister cuidar para não produzir exposições que resultem em verdadeiros "livros na vertical", uma avalanche de textos e imagens que dão suporte aos objetos arqueológicos e que sufocam o visitante com tantas informações que Ihe fica difícil discernir entre o relevante e o irrelevante. A arqueóloga Francisca Hernández Hernández (2012:212), dedicada à caracterização e reflexão a museografia dos museus arqueológicos, ressalta a importância estratégica de escolher entre as diversas formas de exposição aquela mais adequada para atender os objetivos de estudo e fruição desses bens culturais ${ }^{21}$.

$\mathrm{Na}$ atualidade, os maiores desafios que enfrentam os museus de arqueologia dizem respeito a diversos aspectos socioculturais, de âmbito científico, político e econômico dentre os quais destaco a reflexão sobre o papel dos museus na contemporaneidade, o reconhecimento da dimensão política dessas instituições e os desdobramentos da Arqueologia de Contrato, que insere a prática arqueológica na lógica do mercado e sob a dinâmica política e econômica. No Brasil, a Arqueologia de Contrato resulta em um aumento exponencial dos acervos arqueológicos, para os quais as instituições de guarda não estão preparadas para gerir adequadamente, nem a comunidade científica para investigar plenamente e nem os organismos estatais para desenvolver políticas públicas de preservação eficazes (SALADINO, COSTA, MENDONÇA, 2013).

\footnotetext{
21 A autora cita Josef Benês, que caracteriza as diversas formas de exposições museológicas a partir da relação entre elas e a realidade original e reconhece três tipos genéricos, que podem ser subdivididos: a) exposição in situ ou em seu contexto original; a exposição baseada em objetos, sem qualquer referência e informação sobre o contexto de procedência e c) a exposição que procura apresentar as relações dos objetos com o seu contexto original através de diversos meios visuais (HERNÁNDEZ, 2010:209-210).
} 


\section{Algumas provisórias considerações}

As motivações desta reflexão sobre as especificidades, potencialidade e desafios dos museus arqueológicos têm sua origem no reconhecimento do seu papel estratégico na divulgação da Arqueologia e na preservação e valorização do patrimônio arqueológico. Muito embora soe ser este um tema tão básico, elementar, faz-se necessária sua discussão, pois para que os museus arqueológicos atinjam sua plena potência enquanto loci de preservação e valorização daquela categoria de bem cultural, é fundamental escolher com consciência as perspectivas e abordagens a definir a narrativa - ou seja, conhecer suas possibilidades e limites - bem como clareza na apresentação de suas diretrizes afinal, a legitimidade de um conceito se dá pela sua aplicação.

À guisa de conclusão deste ensaio, retomo as questões que the foram o mote sem, entretanto, pretender encerrar o debate, antes sim provocar a reflexão e a emersão de outros e diferentes entendimentos. É possível reconhecer um museu de arqueologia pelo seu acervo e pelo seu discurso, ambos decorrentes da prática arqueológica. Em outras palavras, é um museu que trata da condição humana e da relação da nossa espécie com o meio a partir da exposição de vestígios arqueológicos e da narrativa arqueológica.

As especificidades dos museus arqueológicos referem-se à possibilidade de produzir distintas narrações sobre a condição humana em diversas escalas de tempo, espaço e representação (longa duração, passado recente, nacional, regional, local) e a partir de distintas perspectivas teóricas (histórico-culturalista, processualista, pós-processualista, etc).

Os museus de arqueologia podem tratar de todo e qualquer assunto relacionado à condição humana. Portanto, não há limite de 
Museus e arqueologia: algumas reflexões

temas a abordar a partir dos acervos arqueológicos, afinal não é possível parar de pensar no presente quando se investiga o passado da mesma forma que não é possível parar de pensar no passado quando se analisa o presente. A título de ilustração, destaco dois movimentos que vêm transformando a prática e o discurso dos museus arqueológicos: o primeiro refere-se à discussão sobre a retirada de restos humanos das exposições de longa duração e o reenterramento de restos de ancestrais de minorias étnicas no contexto anglo-saxão (ZAPATERO, 2009:28), bem como no latinoamericano ${ }^{1}$. O segundo refere-se ao repatriamento de peças arqueológicas ${ }^{22}$ Ou seja, os museus arqueológicos, assumindo a sua dimensão político-ideológica, têm tratado de questões contemporâneas relacionadas à diversidade étnico-cultural, à desigualdade social e ao direito de memória. Este ambiente, vale lembrar, sofre influência da Sociomuseologia e da Arqueologia Pública, a partir das quais são repensadas a prática museológica e a prática arqueológica com vistas a promover a sensibilização e o empoderamento dos grupos sociais por meio da apropriação, ressignificação e valorização do patrimônio arqueológico.

Reconhecemos que, devido a fatores variados - como dotação orçamentária insuficiente e quadro funcional reduzido, apenas para citar alguns - instala-se um gap entre as narrativas resultantes das pesquisas arqueológicas mais recentes e o discurso da exposição de longa duração dos museus arqueológicos. Entretanto, na atualidade dispomos de diversos recursos para atenuar esse quadro. Alguns exigem orçamento, outros podem ser desenvolvidos mesmo a custo zero por meio do estabelecimento de parcerias interinstitucionais. A título de ilustração destaco a

${ }^{22}$ Em 2010, o governo da Costa Rica logrou a restituição de vinte e oito objetos da cultura Chavín, até então parte das coleções do Museo de América, de Madrid. Em agosto de 2014 reavivaram-se os debates para restituição ao povo colombiano de cento e vinte e duas peças Chimbaya, igualmente parte do acervo do museu em tela. 
realização de exposições temporárias dedicadas a um ou mais temas tratados na exposição de longa duração, a realização de visitas mediadas, oficinas temáticas (de arqueologia experimental ${ }^{23}$, por exemplo), seminários que conectem comunidade científica, museu e sociedade e a aplicação de recursos tecnológicos (como a realidade ampliada, RCode etc) e, claro, a reformulação do discurso da exposição de longa duração.

O discurso expositivo, à luz da Sociomuseologia e da Arqueologia Pública, deve ter como pilar a articulação das diversas narrativas sobre o patrimônio arqueológico, sejam elas oriundas do campo científico, do social e do político e, justamente por isso, deve ser elaborado de forma participativa e colaborativa por distintos segmentos sociais. A emancipação do indivíduo e o fortalecimento da cidadania podem decorrer das experiências museais, caso seja exposta ao público a manipulação do passado pelo presente suas demandas e caso seja construído um discurso aberto, capaz de provocar a reflexão e o questionamento nos visitantes sobre o dito e o não-dito e o dito de diversas formas e de expor com clareza o seu autor e suas premissas e perspectivas teóricas, para que fique evidente a natureza do discurso científico, qual seja, a sua polifonia. Entretanto, para que tal objetivo seja alcançado de forma efetiva, é necessário que essas experiências museais afetem pelo afeto, estimulem a ressonância do patrimônio arqueológico sobre o público. Para tal, acredito ser pertinente que os museus abdiquem da narrativa cronológica linear ponham a dialogar objetos e temas do passado e do presente, evidenciando assim que, apesar das diferenças temporais e culturais, o bem-estar continua a ser a meta da humanidade.

\footnotetext{
${ }^{23}$ De acordo com Torruela e Tenas (2012:146), a arqueologia experimental permite reproduzir processos com alto teor de conteúdo didático. Entretanto, percebo que seu potencial é ainda maior, à medida que soa ser genuína experiência museal sensorial e afetiva.
} 
Museus e arqueologia: algumas reflexões

Destarte, alinho-me à percepção de Hernández (2010:11) de ser necessário abandonar a definição tecnicista da museografia que a reduz a um conjunto de técnicas e práticas necessárias ao funcionamento do museu - para reconhecer as suas possibilidades de provocar o público e motivá-lo a buscar mais conhecimento e a transformar o seu olhar. Então, não é excessivo lembrar da necessidade de conhecer o público-alvo antes de planejar um projeto museográfico. É necessário ainda identificar e aplicar no discurso expositivo os códigos de significados que o público detém. Isto, claro, se é objetivo da proposta criar condições de os visitantes interpretarem e se apropriarem das mensagens contidas (HERNÁNDEZ, 2010:19). Identificar com precisão o principal destinatário do discurso é igualmente fundamental para utilizar os recursos museográficos mais adequados para atingir os distintos públicos (escolar, comunidade local, turistas etc). Afinal, como lembra Zapatero (2009:14) o "público geral" não existe e é premente reconhecer a diversidade de públicos para uma divulgação eficaz. Em outras palavras, é necessário comunicar aquilo que é interessante e que é possível ser apropriado pelos distintos públicos em vez que priorizar as necessidades da Arqueologia enquanto disciplina (MALLOY \& JEPPON apud ZAPATERO, 2009:14)

Finalmente, os maiores desafios dos museus arqueológicos na era da Arqueologia de Contrato referem-se à gestão desses bens e da documentação correspondente (produzida ao longo de toda a cadeia operatória arqueológica e da cadeia operatória museológica). Não é excessivo lembrar da importância da gestão museológica para o bom desempenho das funções de qualquer museu, que se inicia com um diagnóstico global da instituição para a identificação dos gargalos e fragilidades que possam comprometer a aplicação da cadeia operatória da museologia (CANDIDO, 2013). Entretanto, o planejamento museológico é apenas um dos elementos fundamentais para lidar 
com os desdobramentos da Arqueologia de Contrato. São necessários outros, que ultrapassam os limites institucionais dos museus, pois referem-se à elaboração e implantação de políticas públicas de preservação do patrimônio arqueológico, à definição das atribuições e competências dos organismos envolvidos com a preservação e musealização dessa categoria de bem designadamente IPHAN e Ibram -, à implantação de uma agenda de trabalho conjunta entre eles e, ainda, à boa - e ética - prática profissional.

Os problemas da preservação do patrimônio arqueológico ganham cada vez mais espaço de discussão nos fóruns do campo da Arqueologia e no campo da Museologia (SALADINO, COSTA, MENDONÇA, 2013). Nesses debates fortalece a ideia de que os museus arqueológicos, em sua origem potentes ferramentas colonizadoras, hoje, graças às perspectivas políticas estabelecidas tanto no campo da Arqueologia quanto no campo da Museologia e às diversas feições que podem adquirir (museus nacionais, regionais, locais, comunitários, de território etc), são lugares onde é possível refletir sobre a condição humana e adquirir elementos para inventar uma nova ordem, na qual o discurso científico possa contribuir para a transformação e a libertação a partir do afeto, do estímulo intelectual e da motivação a buscar e cria novos sentidos (RUBIALES, 2009). E, por isso urge o estabelecimento de uma agenda de trabalho coletivo e colaborativo dos diversos profissionais envolvidos nos processos de preservação do patrimônio arqueológico. Assim, os museus de arqueologia podem finalmente deixar de representar a última camada da estratigrafia do abandono da Arqueologia estabelecida no século XX (BRUNO, 2005:235). 
Museus e arqueologia: algumas reflexões

\section{Referências}

ABREU, Regina. (2007). Museus, patrimônios e referências culturais. ABREU, Regina; CHAGAS, Mario; SANTOS, Myrian. Museus, coleções e patrimônios: narrativas polifônicas. Rio de Janeiro: Garamond, MinC/IPHAN/DEMU, p.114-125.

ALVES JR. Mario Polo. (2014). Dos instrumentos jurídicos e práticas do IPHAN para a arqueologia: o termo de ajustamento de conduta. Dissertação de Mestrado. Mestrado Profissional em Preservação do Patrimônio Cultural. Rio de Janeiro: IPHAN, 246p.

ANDERSON, Benedict. (1991). Comunidades imaginadas: reflexões sobre a origem e a expansão do nacionalismo. Lisboa: Edições 70.

BARRETO, Cristiana. (2000). A Construção de um passado précolonial: uma breve história da arqueologia no Brasil. Revista USP, v. 44 , p. 32-51.

BRUNO, Maria Cristina de Oliveira. (2005). Arqueologia e antropofagia: a musealização de sítios arqueológicos. Revista do Patrimônio Histórico e Artístico Nacional. oo 31. Brasília: IPHAN/MinC, p.235-247.

BRUNO, Maria Cristina de Oliveira. (1997). Museologia e museus: princípios, problemas e métodos. Cadernos de Sociomuseologia, no10. Lisboa: Edições Universitárias Lusófonas.

CHAGAS, Mario. (1987). Museu: coisa velha, coisa antiga. Rio de Janeiro: UNIRIO. CÂNDIDO, Manuelina M. D. (2013). Gestão de museus, diagnóstico museológico e planejamento: um desafio contemporâneo. Porto Alegre: Medianiz.

DAWDY, S. L. (2009) Millenial Archaeology: locating the discipline in the age of insecurity. Archaeological Dialogues, 16 (2), p.131-142. FOUCAULT, Michel. (1979). Microfísica do poder. São Paulo: Graal. FOUCAULT, Michel. (1985). As palavras e as coisas: uma arqueologia das ciências humanas. São Paulo: Martins Fontes.

FOUCAULT, Michel. A verdade e as formas jurídicas. (2002). Rio de Janeiro: Nau Ediora. 
FUNARI, Pedro Paulo. (1995/1996). A “República de Palmares" e a arqueologia de Serra da Barriga. Revista USP, São Paulo, (28), p.613.

FUNARI, Pedro Paulo. Arqueologia. (2001). São Paulo: Editora Contexto.

HERNÁNDEZ, F. H. (2010). Los museos arqueológicos y su museografía. Gijón: Ediciones Trea.

LIMA, Tania Andrade. (s.d.). Luiz de Castro Faria, também um arqueólogo. http://centrodememoria.cnpq.br/publicacoes3.html (último acesso: 13/09/2014)

MENESES, Ulpiano Bezerra de. (2007). Premissas para a formulação de políticas públicas em arqueologia. Revista do Patrimônio, no 33, p.37-57.

MOUTINHO, Mário C. (2012). Definição evolutiva de Sociomuseologia: proposta de reflexão. http://www.minomportugal.org/documentos-de-referencia/10-definicao-desociomuseologia/12-proposta-de-definicao-desociomuseologia.html (último acesso: 02/07/2014)

NORA, Pierre. (1993). Entre memória e história: a problemática dos lugares. In: Projeto História, no 10, São Paulo: PUC, p. 7-28.

RUBIALES, Ricardo. (2009). Aprendizaje y museos: breves notas sobre El quehacer museístico. México. http://www.educacionenmuseos.com/educacionenmuseos/ebooks_files/aprendizaje-\%20ebook.pdf (último acesso: 02/07/2014) SHANKS, Michael; TILLEY, Christopher. (1992). Re-constructing Archaeology. London \& New York: Routledge.

SCHWARCZ, Lilia Moritz. (2004). O espetáculo das raças: cientistas, instituições e questão racial no Brasil - 1870-1930. São Paulo: Companhia das Letras.

TAVARES, Reinaldo Bernardes. (2012). Cemitério dos Pretos Novos, Rio de Janeiro, século XIX: uma tentativa de delimitação espacial. Dissertação de Mestrado. Programa de Pós-Graduação em Arqueologia. Rio de Janeiro: UFRJ, 207p. 
Museus e arqueologia: algumas reflexões

TORRUELLA, Maria Feliu; TENAS, Neus Sallés. Didáctica y Arqueología: um tándem imprescindible. CARDONA, Francesc Xavier Hernàndez; ARIZA, María del Carmen Rojo (coords.). (2012). Museografía didáctica e interpretación de espacios arqueológicos. Gijón: Ediciones Trea, p.145-156.

TRIGGER, Bruce. (2004). História do Pensamento Arqueológico. São Paulo, Odysseus.

WICHERS, Camila de Azevedo Moraes. (2010). Museus $e$ Antropofagia do Patrimônio Arqueológico: (des)caminhos da prática brasileira. Tese de Doutoramento em Museologia. Lisboa: Universidade Lusófona de Humanidades e Tecnologias, 483p.

ZAPATERO, Gonzalo Ruiz. (2009). La divulgación arqueológica: las ideologias ocultas. CPAG, 19, p.11-36.

\section{Outras fontes}

Carta de Lausanne. http://portal.iphan.gov.br/portal/baixa FcdAnexo.do?id=262 (último acesso: 02/07/2014) 